\title{
Обучение персонала
}

Ценность информационных технологий - это понятие не абстрактное, оно зависит от наличия людей, умеющих из этих технологий извлекать пользу. Поэтому одним из наиболее важных моментов перехода к работе в условиях изменения или внедрения новых ИТ является обучение персонала.

Квалифицированные сотрудники не только смогут обеспечить стабильность и эффективность работы, но и многократно повысят стоимость самой компании.

$$
\text { *** }
$$

1. Назарова О.Б., Давлеткиреева Л.З. Интеграция автоматизированных информационных систем в сфере продаж холдинговой компании//Актуальные вопросы научной и научно-педагогической деятельности молодых учёных: сборник научных трудов всероссийской заочной научнопрактической конференции/под ред. Е.С. Ефремовой. Москва, 2015. - С. 86-96.

2. Назарова О.Б., Давлеткиреева Л.З., Малахова И.В.Аудит информа-ционной инфраструктуры компании и разработка ИТ-стратегии: монография/О.Б. Назарова, Л.З. Давлеткиреева, И.В. Малахова. -Магнитогорск: Магнитогорский гос. ун-т, 2012. -223 с.

3. Назарова О.Б., Новикова Т.Б., Петеляк В.Е. К вопросу разработки диа-граммы «архитектура системы -ASD»//B сборнике: Современная наука: теоретический и практический взгляд Сборник статей Международной научно-практической конференции. Ответственный редактор: Сукиасян Асатур Альбертович. 2015. С. 75-77.

4. Аудит ИТ-деятельности [Электронный ресурс]. - Режим доступа: http://www.itexpert.ru/rus/consulting/catalogue/inspaudit/audit/

\section{Юркова О.Н.}

Автоматизированная информационная система для оценки принадлежности иностранных студентов к группе риска хронических заболеваний

\author{
ФГБОУ ВО «БГИТУ» \\ (Россия, Брянск)
}

doi:10.18411/spc-12-11-2017-09

idsp: 000001:spc-12-11-2017-09

\section{Аннотация}

Разработана информационная система, в которой автоматизирован процесс прохождения скрининг-теста AUDIT иностранными студентами, одобренного ВO3.

Ключевые слова: автоматизированная информационная система; хронические заболевания; иностранные студенты, скрининг-тест.

Усиление процессов международного сотрудничества, мобильности учащейся молодежи, повышения престижности российского образования приводит к увеличению числа иностранных граждан среди учащихся российских вузов. В то же время уровень здоровья иностранных студентов вызывает особые опасения, потому что не только отсутствуют сведения об исходном состоянии их здоровья, но и существует повышенная вероятность его резкого ухудшения, т. к. стрессорное влияние учебной деятельности и других социальных факторов усугубляется напряжением адаптационных механизмов, связанных со сменой климатических условий проживания. Тем более что климатические условия Брянского региона являются экстремальными для уроженцев Африки, Средней Азии и многих других регионов, резко отличающихся по комплексу ландшафтно-климатических характеристик (уровню инсоляции, температурному режиму, влажности воздуха и т. д.). Поэтому существует повышенный риск возникновения различных заболеваний, в т. ч. хронических и инфекционных. Вместе с тем экспресс-тестирование состояния здоровья иностранных студентов вызывает особые затруднения, связанные с языковыми, организационными и другими проблемами.

На сегодняшний день в России не существует автоматизированной комплексной оценки состояния здоровья иностранных граждан. Существует лишь возможность оценки единичных показателей, например, оценки психоэмоционального состояния, которые используются как для российских, так и иностранных студентов, поскольку в 
большинстве случаев они представлены в виде тестовых заданий, которые испытуемому необходимо выполнить за определенное время.

Для создания и разработки автоматизированной информационной системы были использованы следующие программные средства: Visual Studio 2013 Ultimate; SQLServer2012; Adobe PhotoshopCC 2015; Microsoft Publisher.

Программный модуль позволяет автоматизировать весь процесс скринингтестирования методикой AUDIT на инфомате. Программный модуль состоит из трех программ: AUDITTEST, AUDITDOCTOR, AUDITSTATISTICS, и взаимодействует с двумя базами данных. Структура программного модуля представлена ниже (рис.1).

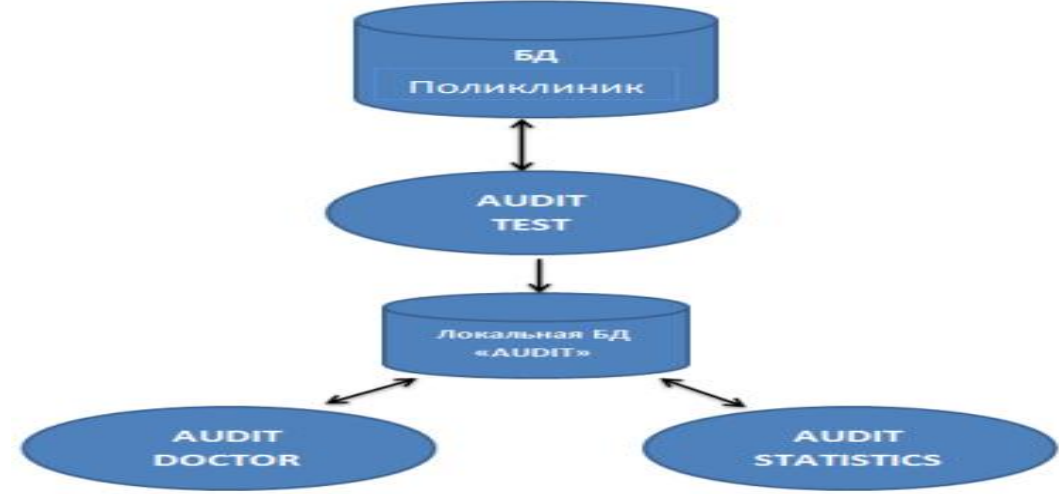

Рисунок 1. Структура программы AUDIT

Кроме локальной базы банных, разрабатываемая информационная система взаимодействует с базой данных поликлиники. Обращение к ней происходит только в модуле «AUDITTEST». Два других модуля работают только с локальной базой данных.

Работа программы начинается с открытие окна формы, на которой пользователь вводит номер своего паспорта (рис. 2). Программа делает обращение к базе данных и возвращает значение переменной пол (М/Ж).

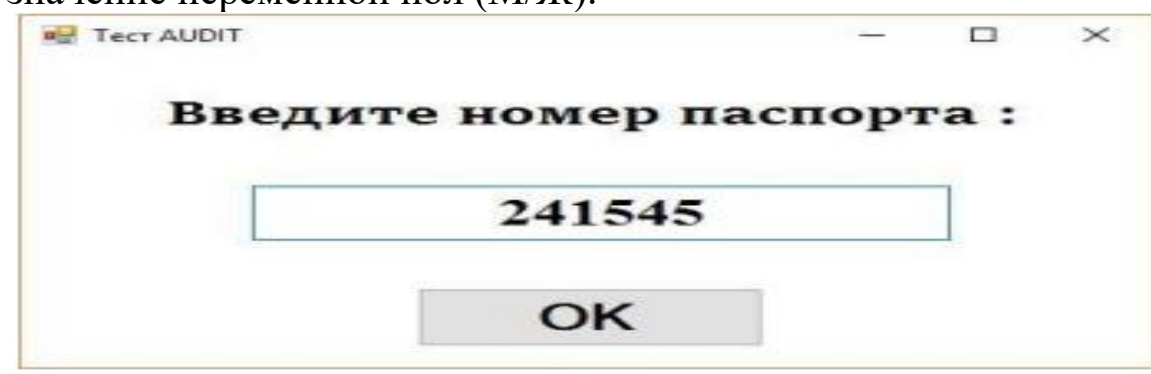

Рисунок 2. Начало работы программы

После нажатия на кнопку «ОК» открывается окно с первым вопросом. Если тестируемый отвечает «нет», то открывается окно завершения работы программы. В этом случае пользователь не попадает в зону риска заболевания. Если тестируемый отвечает «да», то открывается окно со вторым вопросом.

После ответа на все предложенные вопросы открывается форма завершения программы с рекомендациями к дальнейшим действиям (рис. 3). В этом окне отображается информация о набранных баллах и режиме работы кабинета консультаций.

B модуле AUDITDOCTOR для вывода информации о пациенте необходимо ввести ФИО пациента и нажать кнопку «поиск пациента». После чего выводится информация о дате тестирования и количестве набранных баллов. При нажатии на кнопку «открыть ответы пациента» можно подробнее узнать об ответах тестируемого. После проведения мотивационного консультирования пользователь нажимает «Проведена консультация», если фельдшеру удалось мотивировать пациента на сокращение потребления алкогольных напитков - нажимает кнопку «Удалось 
мотивировать». Для подтверждения занесения данных выводится окно подтверждения (рис. 4).

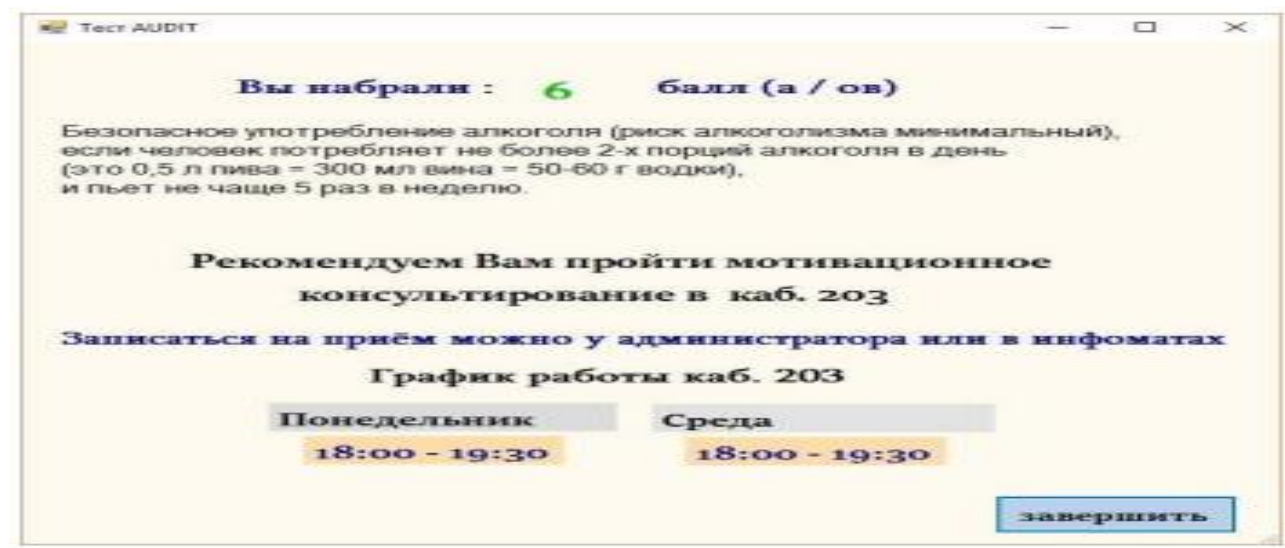

Рисунок 3. Вывод рекомендаџий

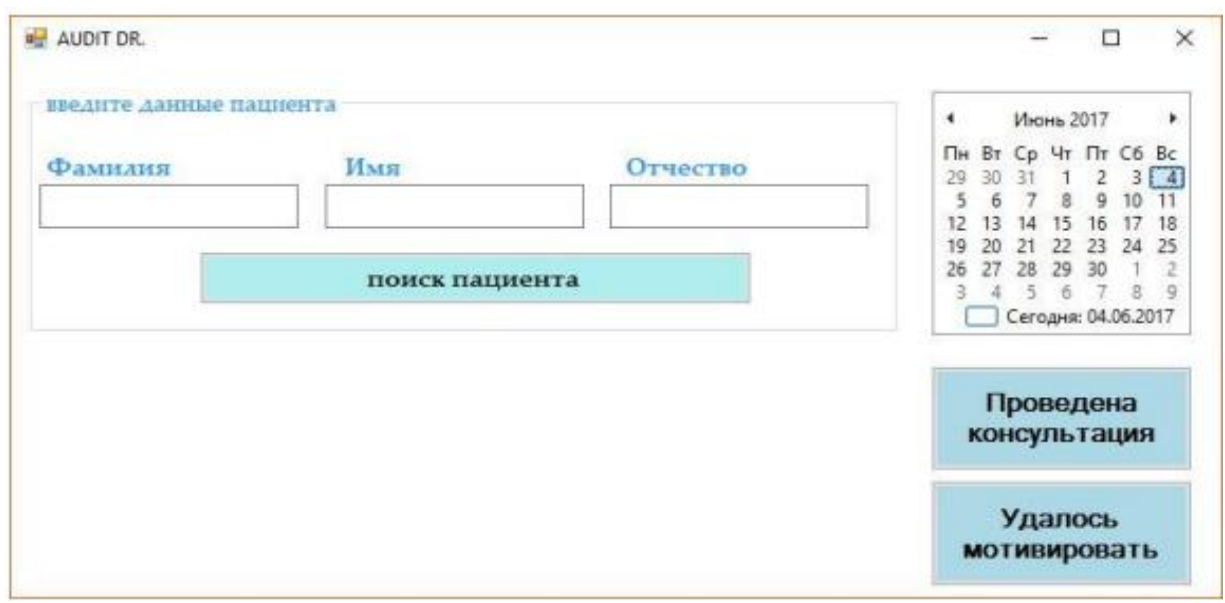

Рисунок 4. Начало работы AUDITDOCTOR

Модуль AUDITSTATISTICS предназначен для про вывода статистики о проведенном тестировании. В данном модуле может быть реализована группировка статистических данных по дате: конкретный период, за все время работы программы и группировка по возрасту тестируемых. Для открытия той или иной формы статистики необходимо выбрать интересующий пункт в окне открытия программы (рис. 5).

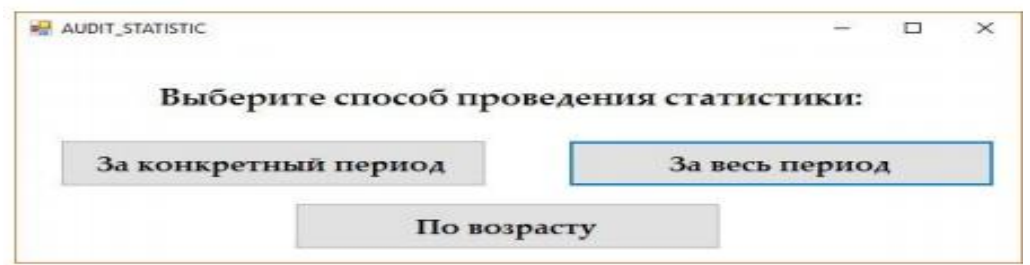

Рисунок 5. Начальное окно AUDITSTATISTICS

Разработанная информационная система является полноценной готовой программой для масштабного использования в больницах и поликлиниках в разных городах России.

$$
* * *
$$

1. Гулин А.В., Шутова С.В., Григорова Л.И., Муравьева И.В., Бе- лов Р.Н., Туманян А.А. Комплексная оценка здоровья иностранных граждан. Тамбов: Издат. дом ТГУ им. Г.Р. Державина, 2012. 55 с 